\title{
Improvement of the geoid model over Japan using integral formulae and combination of GGMs
}

\author{
Patroba Achola Odera ${ }^{1 *}$ and Yoichi Fukuda ${ }^{2}$
}

\begin{abstract}
An improved high-resolution gravimetric geoid model covering the four main islands of Japan (Hokkaido, Honshu, Shikoku, and Kyushu) was developed on a $1 \times 1.5$ arc-minute grid from EGM2008, GOCO02S/EGM2008, and terrestrial gravity data. A modified form of the Stokes-Helmert scheme was applied for the determination of the geoid using an empirically determined optimal spherical cap size. Handling of the topographical effects on gravity was accomplished using the integral formulae of Martinec and Vaníček, which were found to be more suitable for geoid modeling over Japan than the classical formulae. EGM2008 was used in Hokkaido, Honshu, and Kyushu Islands, whereas a combination of GOCO02S and EGM2008 was used in Shikoku Island and its immediate surroundings. The global geopotential models (GGMs) used in this study were chosen based on our earlier evaluation of the performance of EGM2008- and GOCE-related GGMs in Japan. In comparison with the previous geoid model for Japan, our new model shows an improvement in the standard deviation from \pm 8.3 to $\pm 7.5 \mathrm{~cm}$.
\end{abstract}

Keywords: Geoid model; Gravity anomalies; GGMs; Integral formulae; Topographical effects

\section{Background}

Geoid determination over Japan has been the focus of numerous studies over the past few decades (e.g., Ganeko 1976; Kuroishi 1995, 2001a, b, 2009; Fukuda et al. 1997; Kuroda et al. 1997; Kuroishi et al. 2002; Kuroishi and Denker 2001; Kuroishi and Keller 2005; Odera et al. 2012; Odera and Fukuda 2013), although precise geoid modeling remains a challenge. In this study, an improved high-resolution gravimetric geoid model is developed from EGM2008 (Pavlis et al. 2012), GOCO02S (Goiginger et al. 2011) combined with EGM 2008 (GOCO02S/EGM2008), and local terrestrial gravity data. EGM2008 is complete to spherical harmonic degree and order 2,159 and contains additional coefficients extending to degree 2,190 and order 2,159.

The choice of global geopotential models (GGMs) used in this work is based on our earlier evaluation of GGMs that have recently been developed over Japan (Odera and Fukuda 2013). In that study, the performance of EGM2008 and the Gravity field and steady-state Ocean Circulation Explorer (GOCE)-related GGMs that

\footnotetext{
*Correspondence: podera@jkuat.ac.ke

'Department of Geomatic Engineering and Geospatial Information Systems, Jomo Kenyatta University of Agriculture and Technology, P.O. BOX 62000-00200, Nairobi, Kenya

Full list of author information is available at the end of the article
}

were recently released by the European Space Agency were assessed, the latter being based on 2, 8, and 12 months of data collected by GOCE. This assessment was based on geoid undulations, obtained from 816 GPS/leveling points, and free-air gravity anomalies, obtained from 6,951 first-order gravity points. The distribution of these data over the four main islands of Japan is shown in Figure 1.

The evaluated GOCE and related GGMs included GOCE-DIR1, 2, 3 (Pail et al. 2011; Bruinsma et al. 2010), GOCE-TIM1, 2, 3 (Pail et al. 2011; Pail et al. 2010b), GOCE-SPW1, 2 (Migliaccio et al. 2011), and GOCO01S, 02S (Goiginger et al. 2011; Pail et al. 2010a). The performance of EGM2008 and GOCE-related GGMs over Japan was shown by Odera and Fukuda (2013) to be almost identical at a harmonic expansion to degree 150, although EGM2008 performs better at the 180-, 210-, and 240-degree spectral bands. Furthermore, comparisons over the four main islands reveal that EGM2008 performs better than the GOCE and related GGMs in Hokkaido, Honshu, and Kyushu at 180, 210, and 240 degrees. However, the GOCE and related GGMs perform better than EGM2008 in Shikoku.

Odera and Fukuda (2013) developed a gravimetric geoid model for Shikoku and the surrounding area from 


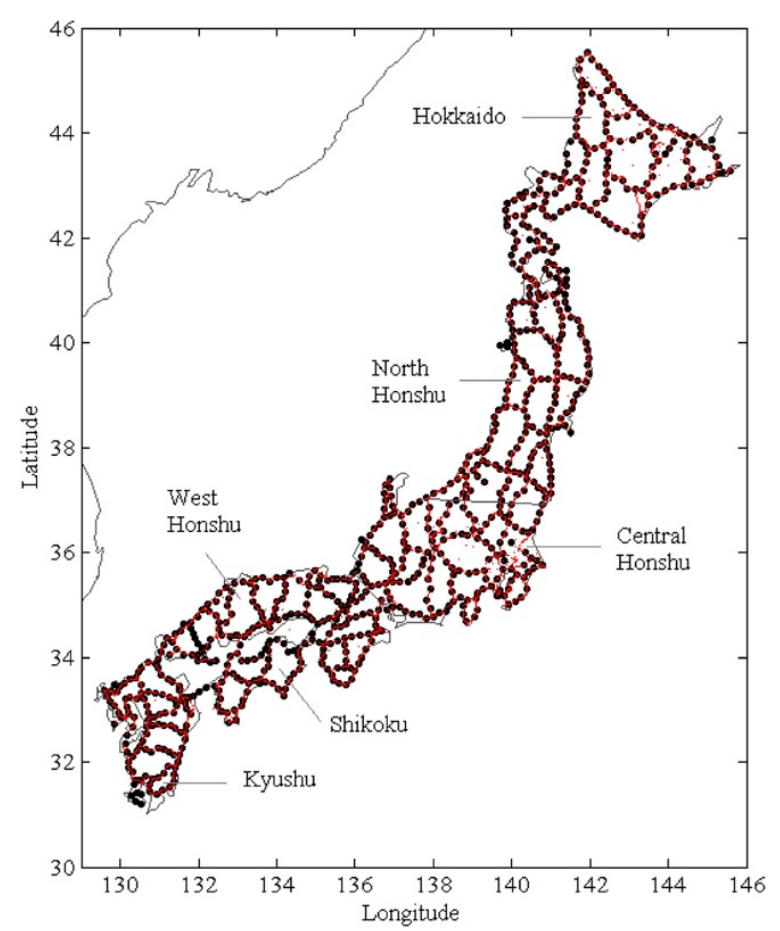

Figure $1 \mathrm{GPS} /$ leveling (big black dots) and first-order gravity (small red dots) over Japan.
GOCE-TIM3/EGM2008 and terrestrial gravity data, with the aim of determining the magnitude of improvement in the model by using GOCE-only data. However, GOCO02S/ EGM2008 performs slightly better than GOCE-TIM3/ EGM2008 in this region. Therefore, in this work, a combination of GOCO02S (up to 180 degrees) and EGM2008 (from 181 to 2,190 degrees) is used to improve the geoid model over the Shikoku area, and EGM2008 is used in Hokkaido, Honshu, and Kyushu. Ship-track gravity data and satellite altimetry-derived marine gravity anomalies in the coastal areas were not considered because of the use of a high-resolution gravitational model (EGM2008). Furthermore, the interest of this study is limited to the land areas.

The classical Moritz formula (Moritz 1980) and a planar formula (Wichiencharoen 1982b) were used to compute the direct topographical effect (DTE) and the primary indirect topographical effect (PITE), respectively, in the previous geoid model for Japan. These two formulae (classical Moritz and planar) are hereafter referred to as the classical formulae and are given respectively as

$$
C=\frac{G \rho_{0} R^{2}}{2} \iint_{\sigma} \frac{\left(H-H_{P}\right)^{2}}{l_{o}^{3}} d \sigma
$$

$$
N_{\text {ind }}=\frac{-\pi G \rho_{0} H_{P}^{2}}{\gamma}-\frac{G \rho_{0} R^{2}}{6 \gamma} \iint_{\sigma} \frac{H^{3}-H_{P}^{3}}{l_{o}^{3}} d \sigma,
$$

where $C$ is the DTE, $N_{i n d}$ is the PITE, $G$ is the Newtonian gravitational constant, $\rho_{0}$ is the constant topographic density, $H_{P}$ is the orthometric height of the computation point, $H$ is the height of the running point, $\sigma$ is the surface integration element, and $l_{o}$ is the horizontal distance between the computation point and the running point.

The current geoid model for Japan has been developed using the integral formulae of Martinec and Vaníček (1994a, b) for the computation of DTE and PITE. Details concerning the procedure and data sets used to develop the previous geoid model can be found in Odera et al. (2012), these being generally the same as for the current computations, with the exception of topographical reductions.

This study further assesses the appropriate topographical gravity reduction procedure for precise geoid modeling in Japan. Gridding of the residual gravity anomalies is accomplished by kriging (Krige 1951) on a $1 \times 1.5$ arcminute grid, Stokes's integral formula (Stokes 1849; Heiskanen and Moritz 1967) is used for geoid determination, and the modified Stokes's kernel proposed by Meissl (1971) is applied to minimize truncation errors.

\section{Methods}

\section{Gravity data reductions and gridding}

Most of the gravity data used in this study was obtained from a database developed by Nagoya University and other organizations that covers the southwestern parts of Japan (e.g., Shichi and Yamamoto 2001a, b). Another set of gravity data, mostly along the main leveling network covering the four main islands (Hokkaido, Honshu, Kyushu, and Shikoku), was provided by the Geospatial Information Authority of Japan (GSI). In total, there are 98,670 observed gravity data points in the study area that were obtained during the observation period approximately 1910 to 2001 (Figure 2). It should be noted that the northern parts of Japan (above latitude $37^{\circ} \mathrm{N}$ ) are sparsely populated with gravity data points, whereas the southern parts are densely populated; however, most of these data was clustered together and even the wellcovered areas contain wide data gaps.

Digital elevation models (DEMs) covering the four main islands were prepared in 1999 by the GSI. The Hokkaido area is covered by a $250-\mathrm{m}$ DEM, whereas the other three main islands (Honshu, Shikoku, and Kyushu) are covered by a $50-\mathrm{m}$ DEM. Both the DEMs and gravity data coordinates are based on the Tokyo Datum, and so an initial datum transformation to the Japanese Geodetic Datum 2000 (JGD2000) was carried out for DEMs and the gravity data. Figure 3 shows the approximate topography of the study area. 


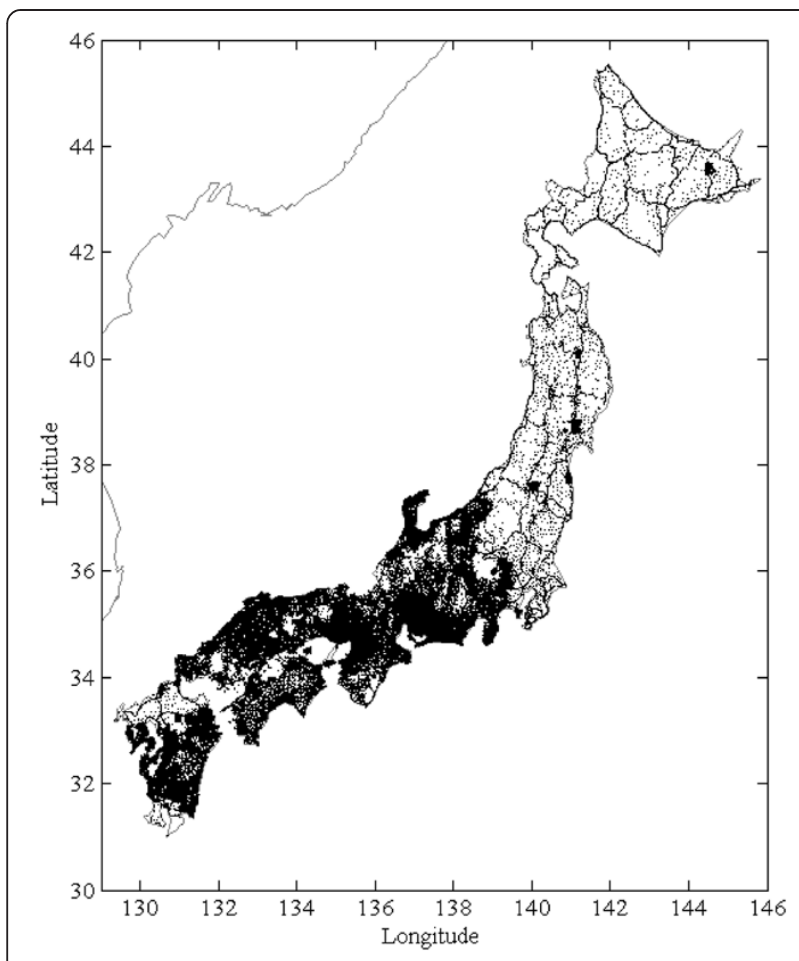

Figure 2 Distribution of gravity data over the four main islands of Japan.

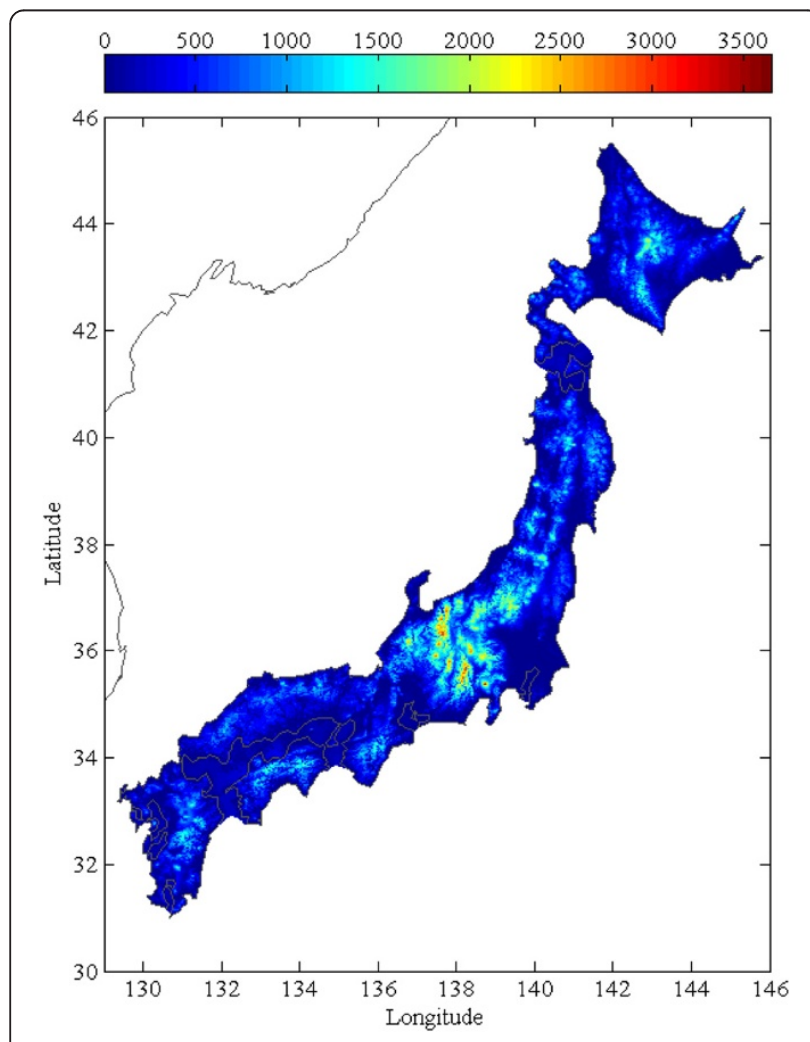

Figure 3 Topography of the study area (units in $\mathrm{m}$ ).
Table 1 Statistics of the topographical effects over Japan

\begin{tabular}{lcccc}
\hline & Min & Max & Mean & S.D. \\
\hline DTE by classical Moritz formula (mGal) & 0.00 & 75.98 & 2.75 & 3.75 \\
$\begin{array}{l}\text { DTE by integral formula of Martinec } \\
\text { and Vaníček (mGal) }\end{array}$ & -40.48 & 49.46 & 2.78 & 4.74 \\
PITE by planar formula (cm) & -40.73 & 37.54 & -1.03 & 2.50 \\
$\begin{array}{l}\text { PITE by integral formula of Martinec } \\
\text { and Vanícek (cm) }\end{array}$ & -88.22 & 0.05 & -1.82 & 4.71 \\
\hline
\end{tabular}

The method chosen for downward continuation of observed gravity on the topographical surface to the geoid plays a central role in precise geoid determination. Stokes's formula for the gravimetric geoid determination requires that no masses occur outside of the geoid and that the gravity anomaly should be referred to the geoid. This reduction was performed following the approach applied by Odera et al. (2012) to the previous geoid model for Japan. Although the classical Moritz formula (Moritz 1980) was used to estimate DTE in the previous geoid model for Japan, here, we evaluated DTE using the integral formula of Martinec and Vaníček (1994b). While both formulae use average topographic density, it should be noted that the classical Moritz formula is also based on the assumption that the distance between the computation and the running point is much greater than the

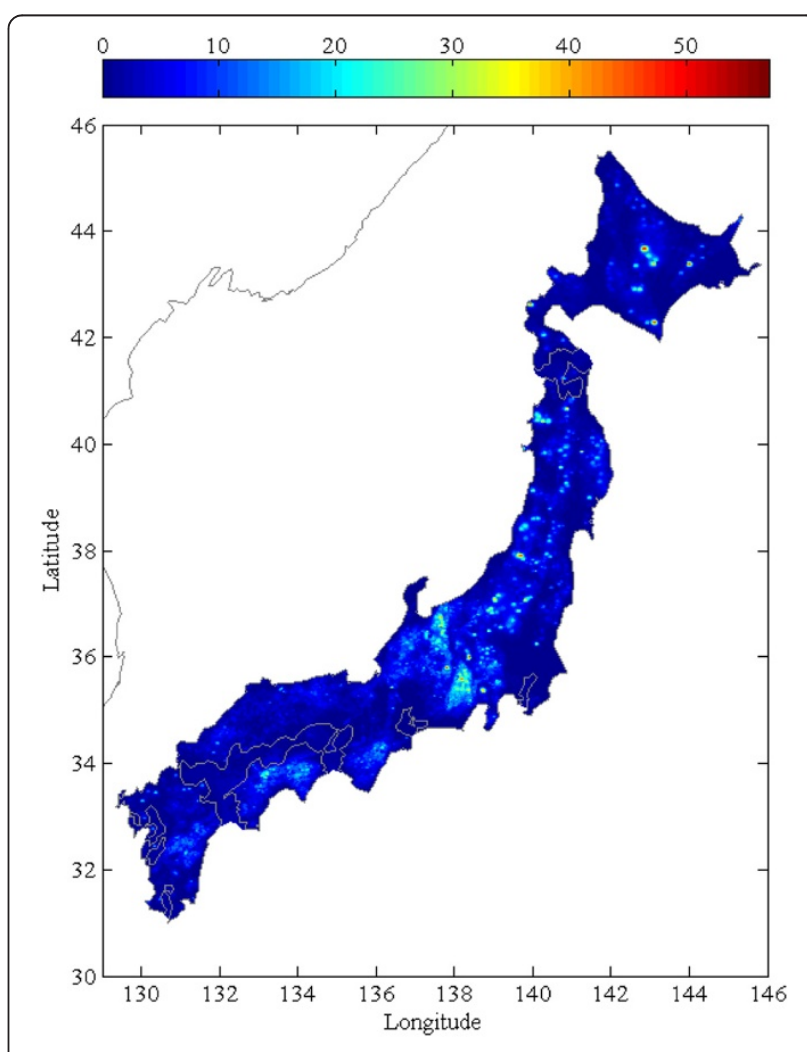

Figure 4 DTE by classical Moritz formula over Japan (units in mGal). 


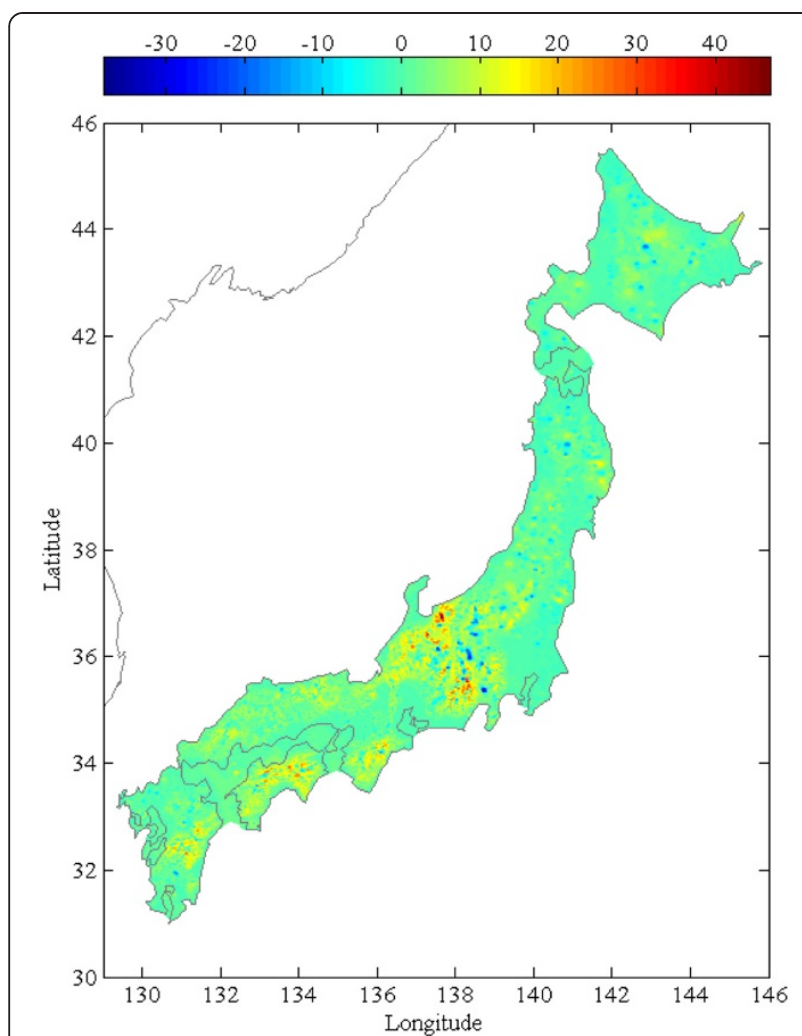

Figure 5 DTE by integral formula of Martinec and Vaníček over Japan (units in mGal).

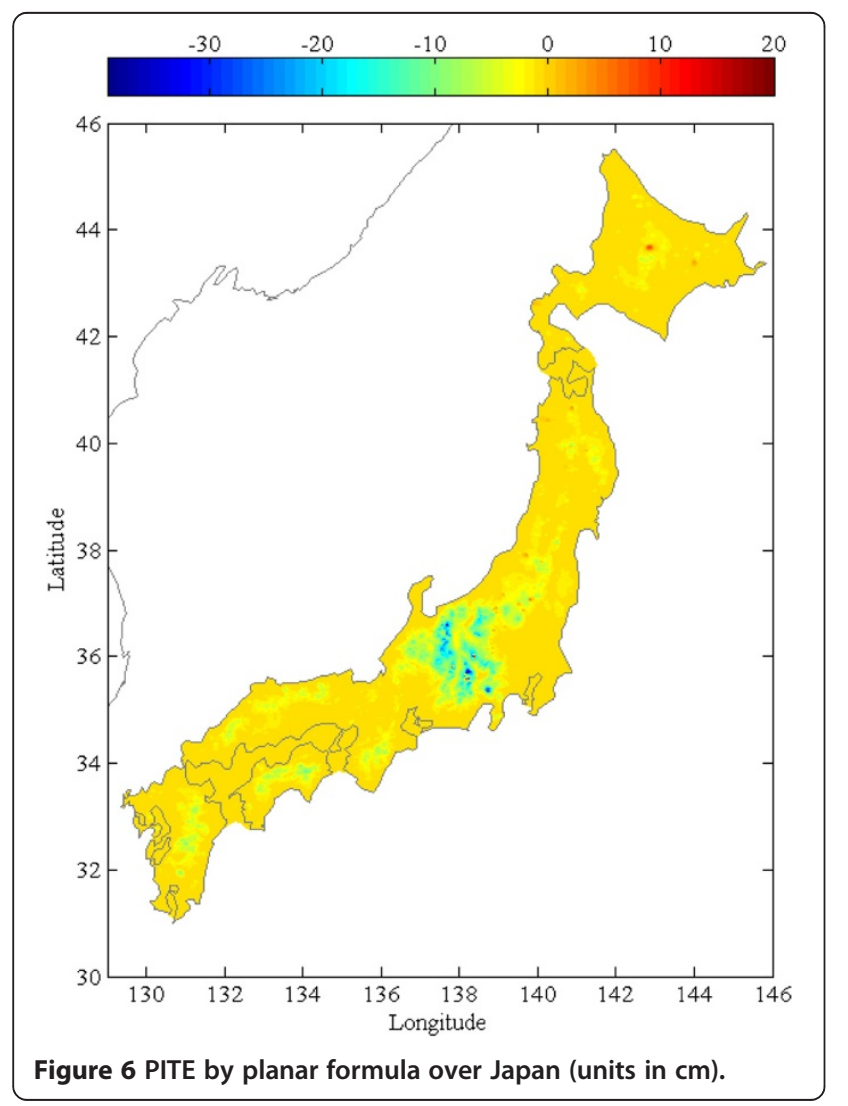

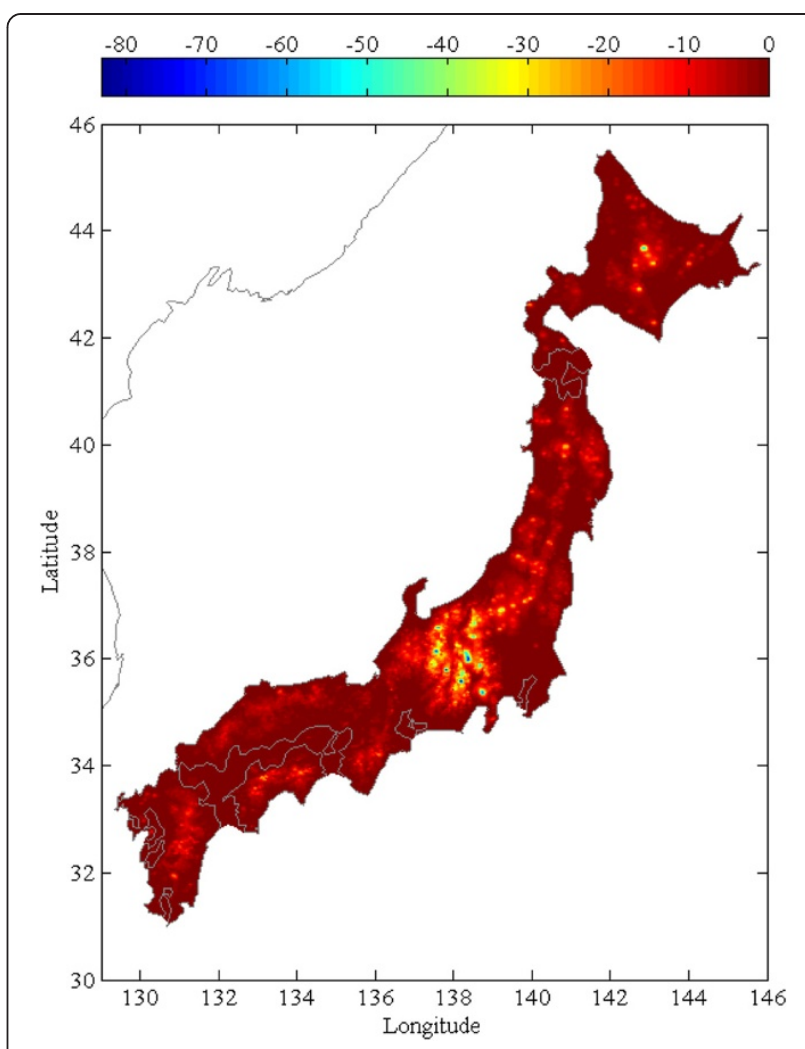

Figure 7 PITE by integral formula of Martinec and Vaníček over Japan (units in $\mathrm{cm}$ ).

height of the computation point $\left(l_{o} \gg H_{P}\right)$, which implies that it can only be used effectively for the far-zone integration area (Martinec et al. 1996). As a result, the effect of the near zone and the Bouguer shell, which cannot be derived in the planar model, is completely missing (e.g., Martinec and Vaníček 1994a; Nahavandchi 2000).

In an attempt to account for the contribution of the near zone, Martinec and Vaníček (1994b) divided the integration area $(\sigma)$ into a near zone $\left(\sigma_{1}\right)$ and a far zone $\left(\sigma_{2}\right)$ based on a spherical approximation of the geoid. The resulting expression for DTE is given as (Martinec and Vaníček 1994b)

$$
\begin{aligned}
C & =-\frac{4 \pi G \rho_{0}}{R} H_{P}^{2}+\frac{G \rho_{0} R^{2}}{2} \iint_{\sigma_{1}} \frac{H^{2}-H_{P}^{2}}{l^{3}}\left(1-\frac{3 H_{P}^{2}}{l^{2}}\right) d \sigma \\
& +\frac{G \rho_{0} R^{2}}{2} \iint_{\sigma_{2}} \frac{H^{2}-H_{P}^{2}}{l_{o}^{3}}\left(1-3 \sin ^{2} \frac{\psi}{2}\right) d \sigma,
\end{aligned}
$$

where $R$ is the mean radius of the Earth, $H_{P}$ is the height of the computation point, $H$ is the height of the running point, $\sigma$ is the surface integration element, $\rho_{0}$ is the average topographic density, and $G$ is the Newtonian gravitational constant. The spatial distances $l$ and $l_{o}$ between the computation and the running points are given respectively as 


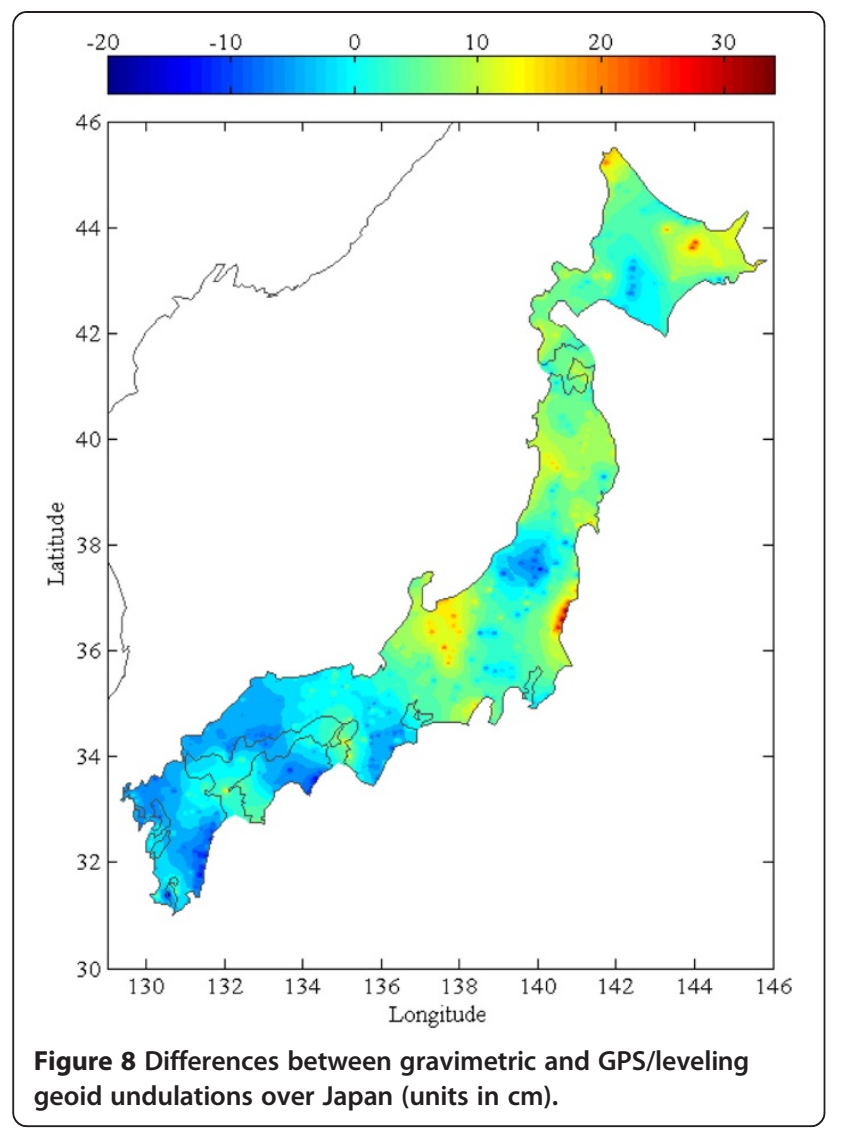

$$
l=\left(r^{2}+R^{2}-2 r R \cos \psi\right)^{\frac{1}{2}}
$$

and

$$
l_{o}=2 R \sin \frac{\psi}{2}
$$

where $r$ is approximated as $R+H_{P}$.

The near zone is defined by the spherical distance $\left(\psi_{0}\right)$ given by Martinec and Vaníček (1994b) as

$$
\psi_{0}=\sqrt{\frac{H_{P}}{R}}
$$

The corresponding PITE on the geoid (e.g., Martinec and Vaníček 1994a) is given as

$$
\begin{aligned}
N_{\text {ind }} & =-\frac{2 \pi G \rho_{0} H_{P}^{2}}{\gamma}+ \\
& +\frac{G \rho_{0} R^{2}}{\gamma} \int_{\sigma}\left[2 \frac{\sqrt{l_{o}^{2}+H^{2}}-\sqrt{l_{o}^{2}+H_{P}^{2}}}{R}+\operatorname{In} \frac{\frac{l_{o}}{2 R}+H+\sqrt{l_{o}^{2}+H^{2}}}{\frac{l_{o}}{2 R}+H_{P}+\sqrt{l_{o}^{2}+H_{P}^{2}}}-\frac{H-H_{P}}{l_{o}}\right] d \sigma .
\end{aligned}
$$

The other applied reductions include a secondary indirect topographical effect (Vaníček et al. 1999), a second-order free-air reduction (Heiskanen and Moritz 1967), and an atmospheric correction (Wichiencharoen 1982a). The residual gravity anomalies are obtained from the reduced gravity anomalies on the geoid and gravity anomalies obtained from EGM2008 (degree 2,190 and order 2,159) in the three islands (Hokkaido, Honshu, and Kyushu), and GOCO02S/EGM2008 (degree 2,190 and order 2,159) in Shikoku. Kriging (Krige 1951) on a $1 \times 1.5$ arc-minute grid was performed for gridding of the residual gravity anomalies.

\section{Geoid modeling over Japan}

Although Stokes's integral formula for geoid determination (Stokes 1849; Heiskanen and Moritz 1967) was applied in this study, it requires that continuous gravity data be available and be used over the entire Earth. As this condition is not currently satisfied, a removecompute-restore procedure was adopted here whereby a GGM provides the long-wavelength geoid undulations, a modified Stokes's formula provides the medium-wavelength components, and the indirect effect provides the short-wavelength components. In addition, the modified Stokes's kernel proposed by

\begin{tabular}{|c|c|c|c|c|c|}
\hline Area & Points & $\operatorname{Min}(\mathrm{cm})$ & $\operatorname{Max}(\mathrm{cm})$ & Mean $(\mathrm{cm})$ & S.D. $(\mathrm{cm})$ \\
\hline Hokkaido & 163 & $-7.88(-12.28)$ & $27.54(25.93)$ & $6.82(2.52)$ & $6.22(6.71)$ \\
\hline North Honshu & 171 & $-14.19(-14.97)$ & 22.18 (19.67) & $6.07(3.17)$ & $6.90(6.41)$ \\
\hline Central Honshu & 163 & $-7.81(-13.99)$ & 36.67 (34.92) & $7.70(1.44)$ & $7.14(7.34)$ \\
\hline West Honshu & 158 & $-8.98(-17.32)$ & $21.16(15.22)$ & $-1.04(-6.93)$ & $4.93(5.16)$ \\
\hline Shikoku & 56 & $-14.27(-23.37)$ & $16.98(21.49)$ & $-0.34(-8.38)$ & $6.55(8.69)$ \\
\hline Kyushu & 105 & $-21.58(-31.50)$ & 9.37 (3.07) & $-2.77(-9.32)$ & $5.18(5.58)$ \\
\hline Whole & 816 & $-21.58(-31.50)$ & 36.67 (34.92) & $3.59(-1.66)$ & $7.48(8.29)$ \\
\hline
\end{tabular}
Meissl (1971) was used to minimize truncation errors. Hence, the expanded modified Stokes's formula,

Table 2 Statistics of the differences between gravimetric and GPS/leveling geoid undulations over Japan and the six sub-regions

Values in parentheses represent geoid differences with respect to the previous geoid model. 
excluding small errors due to ellipsoidal effects, is given as

$$
N=N_{\mathrm{GGM}}+\frac{R}{4 \pi \gamma} \iint_{\sigma_{o}} \Delta g^{r} S^{\mathrm{ME}}(\psi) d \sigma+N_{\text {ind }},
$$

where $N$ is the gravimetric geoid undulation, $N_{G G M}$ is the geoid undulation obtained from EGM2008 or GOCO02S/EGM2008 after applying the zero-degree term (with respect to GRS80), $\Delta g^{r}$ is the residual gravity anomaly, $N_{\text {ind }}$ is the indirect topographical effect, and $S^{M E}(\psi)$ is Meissl's modified kernel.

The optimal spherical distance was evaluated empirically by comparing gravimetric and GPS/leveling geoid undulations at various spherical distances. These comparisons were performed at all 816 GPS/leveling points, and a standard deviation (S.D.) was computed for each spherical distance. As a result, a spherical cap size of $40 \mathrm{~km}$ was adopted for computations in this study because it gives the smallest S.D. when compared to the other spherical distances tested.

\section{Results and discussion}

Statistics relating to the topographical effects (computed by the integral formulae) and the corresponding values (computed by the classical formulae) are presented in Table 1. Computations were performed at the gravity data points.

Figures 4 and 5 show the spatial distribution of DTE over Japan as computed by the classical Moritz formula and the integral formula of Martinec and Vaníček, respectively. Figures 6 and 7 show the spatial distribution of PITE over Japan as computed by a planar formula and the integral formula of Martinec and Vaníček, respectively. It should be noted that the spatial representation of the topographic effects over Japan was achieved by interpolation of the values from the gravity data points onto a $1 \times 1.5$ arc-minute grid for plotting, thus explaining why the minimum and maximum limits in Table 1 may vary slightly from those shown in Figures 4, $5,6,7$.

The differences between gravimetric and GPS/leveling geoid undulations over Japan are shown in Figure 8, and the statistics of these comparisons are given in Table 2 . The statistics of the differences between the previous gravimetric and GPS/leveling geoid undulations are also given in Table 2 in parentheses for comparison.

Table 2 shows that the West Honshu area has the smallest S.D. $( \pm 4.9 \mathrm{~cm})$ between the gravimetric and GPS/leveling geoid undulations, while Central Honshu (a mountainous area) has the largest $( \pm 7.1 \mathrm{~cm})$. When comparing these 816 GPS/leveling data points with the previous geoid model for Japan (Odera et al. 2012), there is a marked improvement in the overall S.D. from \pm 8.3 to $\pm 7.5 \mathrm{~cm}$.
It is evident that much of the improvement of the geoid is due to this study's treatment of the topography, given that the same data sets have been used for both models. For example, if EGM2008 is used over the four main islands (Hokkaido, Honshu, Shikoku, and Kyushu) and integral formulae are applied for the computation of topographic effects, the S.D. between gravimetric and GPS/leveling geoid undulations over the whole of Japan is $\pm 7.6 \mathrm{~cm}$, whereas it is $\pm 8.7 \mathrm{~cm}$ over Shikoku only. Hence, the integral formulae of Martinec and Vaníček (1994a, b) seem to be more suitable for computing the DTE and PITE over Japan than the classical formulae. We also note the interesting effect of a deterioration of the S.D. over North Honshu as opportunity for further investigation. We suggest therefore that a significant improvement in the geoid model over Shikoku, from $\pm 8.7 \mathrm{~cm}$ previously to $\pm 6.6 \mathrm{~cm}$ currently, is mainly due to the contribution of GOCE data.

\section{Conclusions}

We described a procedure for the computation of an improved high-resolution gravimetric geoid model over Japan that exploits the currently available data sets. The integral formulae of Martinec and Vaníček (1994a, b) were used to compute the DTE and PITE over Japan for the first time and were found to perform better than the classical formulae over the studied area. A combination of GOCO02S and EGM2008 (GOCO02S/EGM2008) was used for geoid determination in the Shikoku area, while EGM2008 was used for geoid determination in the remaining islands (Hokkaido, Honshu, and Kyushu).

When comparing these $816 \mathrm{GPS} /$ leveling data points with the previous gravimetric geoid model for Japan, a marked improvement in the overall S.D. from \pm 8.3 to $\pm 7.5 \mathrm{~cm}$ was observed. It was noted that much of the improvement in the accuracy of the geoid over the study area was due to the use of the integral formulae for handling the topographical effects on gravity.

With the recent improvements in geoid determination techniques, the handling of the DTE and PITE needs further attention. However, the need for denser coverage and more accurate gravity data over Japan cannot be overemphasized. Despite this, the gravimetric geoid model obtained in this study performs significantly better than the previous versions and makes an important contribution towards the establishment of a geoidconsistent vertical datum over Japan.

\section{Competing interests}

The authors declare that they have no competing interests.

\section{Authors' contributions}

PAO and YF designed the research, and YF facilitated the data acquisition and interpretation. PAO carried out the computations and related analyses. $\mathrm{He}$ also wrote and revised the paper. Both authors read and approved the final manuscript. 


\section{Acknowledgements}

We would like to thank the Geospatial Information Authority of Japan for providing GPS/leveling and other additional data sets covering the study area. We appreciate the efforts of Nagoya University and other organizations for developing and providing a detailed gravity database covering the southwestern parts of Japan. We are grateful to Prof. Zdeněk Martinec and an anonymous reviewer for their constructive comments and suggestions that have helped to improve the paper.

\section{Author details}

'Department of Geomatic Engineering and Geospatial Information Systems, Jomo Kenyatta University of Agriculture and Technology, P.O. BOX 62000-00200, Nairobi, Kenya. ${ }^{2}$ Graduate School of Science, Kyoto University, Kitashirakawa Oiwake-cho, Sakyo-ku, Kyoto 606-8502, Japan.

\section{Received: 2 August 2013 Accepted: 6 November 2013} Published: 28 April 2014

\section{References}

Bruinsma SL, Marty JC, Balmino G, Biancale R, Förste C, Abrikosov O, Neumayer H (2010) GOCE gravity field recovery by means of the direct numerical method. Paper presented at the ESA living planet symposium, Bergen

Fukuda Y, Kuroda J, Takabatake Y, Itoh J, Murakami M (1997) Improvement of JGEOID93 by the geoidal heights derived from GPS/levelling survey. In: Segawa J, Fujimoto H, Okubo S (ed) Gravity, geoid and marine geodesy, IAG symposia 117. Tokyo, 30 Sept-5 Oct 1996, pp 589-596

Ganeko Y (1976) Astrogeodetic geoid of Japan. Special report 372. Smithsonian Astrophysical Observatory

Goiginger H, Höck E, Rieser D, Mayer-Gürr T, Maier A, Krauss S, Pail R, Fecher T, Gruber T, Brockmann JM, Krasbutter I, Schuh WD, Jäggi A, Prange L, Hausleitner W, Baur O, Kusche J (2011) The combined satellite-only global gravity field model GOCO02S. Presented at the 2011 General Assembly of the European Geosciences Union, Vienna

Heiskanen W, Moritz H (1967) Physical geodesy. Freeman WH, San Francisco

Krige DG (1951) A statistical approach to some basic mine valuation problems on the Witwatersrand. J Chem Metall Min Soc S Afr 52(6):119-139

Kuroda J, Takabatake J, Matsushima M, Fukuda Y (1997) Integration of gravimetric geoid and GPS/levelling survey by least squares collocation (in Japanese). J Geogr Surv Inst 87:1-3

Kuroishi Y (1995) Precise gravimetric determination of geoid in the vicinity of Japan. Bull Geogr Surv Inst 41:1-93

Kuroishi Y (2001a) An improved gravimetric geoid for Japan, JGEOID98, and relationships to marine gravity data. J Geod 74(11-12):745-755

Kuroishi Y (2001b) A new geoid model for Japan, JGEOID2000. In: Sideris MG (ed) Gravity, geoid and geodynamics 2000, IAG symposia 123, Banff, 31 July-4 Aug 2000, pp 329-333

Kuroishi Y (2009) Improved geoid determination for Japan from GRACE and a regional gravity field model. Earth Planets Space 61:807-813

Kuroishi Y, Denker H (2001) Development of improved gravity field models around Japan. In: Sideris MG (ed) Gravity, geoid and geodynamics 2000 IAG symposia 123, Banff, 31 July-4 Aug 2000, pp 317-322

Kuroishi Y, Keller W (2005) Wavelet approach to improvement of gravity field-geoid modelling for Japan. J Geophys Res 110:B03402

Kuroishi Y, Ando H, Fukuda Y (2002) A new hybrid geoid model for Japan, GSIGEO 2000. J Geod 76:428-436

Martinec Z, Vaníček P (1994a) The indirect effect of topography in the Stokes-Helmert technique for a spherical approximation of the geoid. Manuscr Geodaet 19:213-219

Martinec Z, Vaníček P (1994b) Direct topographical effect of Helmert's condensation for a spherical approximation of the geoid. Manuscr Geodaet 19:257-268

Martinec Z, Vaníček P, Mainville A, Véronneau M (1996) Evaluation of topographical effects in precise geoid computation from densely sampled heights. J Geod 70:746-754

Meissl P (1971) Preparations for the numerical evaluation of second-order Molodensky-type formulas. Report 163, Department of Geodetic Science \& Surveying, Ohio State University, Columbus

Migliaccio F, Reguzzoni M, Gatti A, Sansò F, Herceg M (2011) A GOCE-only global field model by the space-wise approach. In: Proceedings of the 4th international GOCE user workshop, Munich, 31 Mar-1 Apr 2011

Moritz H (1980) Advanced physical geodesy. Wichmann Verlag, Karlsruhe
Nahavandchi H (2000) The direct topographical correction in gravimetric geoid determination by the Stokes-Helmert method. J Geod 74(6):488-496

Odera PA, Fukuda Y (2013) Towards an improvement of the geoid model in Japan by GOCE data: a case study of the Shikoku area. Earth Planets Space 65(4):361-366

Odera PA, Fukuda Y, Kuroishi Y (2012) A high-resolution gravimetric geoid model for Japan from EGM2008 and local gravity data. Earth Planets Space 64(5):361-368

Pail R, Goiginger H, Mayrhofer R, Schuh WD, Brockmann JM, Krasbutter I, Höck E, Fecher T (2010a) Global gravity field model derived from orbit and gradiometry data applying the time-wise method. Presented at the ESA living planet symposium, Bergen, 27 June-2 July 2010

Pail R, Goiginger H, Schuh WD, Höck E, Brockmann JM, Fecher T, Gruber T, Mayer-Gürr T, Kusche J, Jäggi A, Rieser D (2010b) Combined satellite gravity field model GOCO01S derived from GOCE and GRACE. Geophys Res Lett 37 L20314

Pail R, Bruinsma S, Migliaccio F, Förste C, Goiginger H, Schuh WD, Höck E, Reguzzoni M, Brockmann JM, Abrikosov O, Veicherts M, Fecher T, Mayrhofer R, Krasbutter I, Sansò F, Tscherning CC (2011) First GOCE gravity field models derived by three different approaches. J Geod 85(11):819-843

Pavlis NK, Holmes SA, Kenyon SC, Factor JK (2012) The development and evaluation of the Earth gravitational model 2008 (EGM2008). J Geophys Res 117:B04406

Shichi R, Yamamoto A (2001a) List of gravity data measured by Nagoya University. Special report 9. Part I, Bulletin of the Nagoya University Museum,

Shichi R, Yamamoto A (2001b) List of gravity data measured by organizations other than Nagoya University. Special report 9. Part II, Bulletin of the Nagoya University Museum,

Stokes GG (1849) On the variation of gravity on the surface of the Earth. Trans Camb Philos Soc 8:672-695

Vaníček P, Huang J, Novák P, Pagiatakis S, Véronneau M, Martinec Z, Featherstone WE (1999) Determination of the boundary values for the Stokes-Helmert problem. J Geod 73(4):180-192

Wichiencharoen C (1982a) FORTRAN programs for computing geoid undulations from potential coefficients and gravity anomalies. Internal report. Department of Geodetic Science and Surveying, Ohio State University, Columbus

Wichiencharoen C (1982b) The indirect effects on the computation of geoid undulations. Report 336. Department of Geodetic Science and Surveying, Ohio State University, Columbus

doi:10.1186/1880-5981-66-22

Cite this article as: Odera and Fukuda: Improvement of the geoid mode over Japan using integral formulae and combination of GGMs. Earth, Planets and Space 2014 66:22.

\section{Submit your manuscript to a SpringerOpen ${ }^{\circ}$ journal and benefit from:}

- Convenient online submission

- Rigorous peer review

- Immediate publication on acceptance

- Open access: articles freely available online

- High visibility within the field

- Retaining the copyright to your article

Submit your next manuscript at $>$ springeropen.com 